The International Journal of E-Learning and Educational Technologies in the Digital Media (IJEETDM) 2(2): 80-85

The Society of Digital Information and Wireless Communications (SDIWC), Apr - 2016 (ISSN: 2410-0439)

\title{
CPMS: A Blackboard Building Block for Managing Capstone Projects
}

\author{
Achraf El Allali, Saad Alessa, Rashed Aldabas, Saud Alsaeed \\ King Saud University, College of Computer and Information Sciences, \\ Department of Computer Science, Saudi Arabia \\ \{eachraf, saad.22.se, mr.aldabas, minesaud\}@gmail.com
}

\begin{abstract}
Learning management systems (LMS) provide students and instructors with an environment to virtually access and manage all aspect of their courses. Students can access course material and submit their work online; while instructors can organize their courses, add content, evaluation students, grade their work and communicate with them. Blackboard is one of the most commonly used LMS systems nowadays. In this paper, we introduce a blackboard building block, which is an extension to the blackboard system that enables management of capstone projects. Most capstone projects are managed using multiple independent systems, using in-house learning management systems, and sometimes on paper. Since most institutions use blackboard, we introduce a blackboard building block that integrates the capstone project process into blackboard. The building block takes advantage of existing blackboard features, while allowing capstone specific processes to take place on the same system. The new extension can be customized during installation to tailor the capstone project process adopted by the institution. For illustration, we follow the process used at the department of computer science at King Saud University.
\end{abstract}

\section{KEYWORDS}

Learning Management System (LMS), Blackboard, Elearning, Educational technology.

\section{INTRODUCTION}

The capstone project at the department of computer science at king Saud University (KSU) consists of two courses that span the senior year. During the first course, students formulate the problem they are addressing, survey the literature and design their solution. A committee of faculty members examine different deliverables throughout the semester as well as the final report and presentation for each groups. During the second capstone project course, students must implement their solutions and present their results and final documentation to the same examination committee.

In the past, this process was carried out through several subsystems, some of which were paper based and others were electronic. The lack of a centralized system that enables the capstone committee to manage project proposals, submissions and grades renders the management of capstone project inefficient and sometime inaccurate. The goal of this paper is to introduce a new integrated system designed to combine and integrate different systems into an existing learning management system. The idea is to combine current systems without adding more burden on the students and the faculty. Like many other universities, KSU uses the blackboard system as the official learning management system. Therefore, we implement a Blackboard [1] extension (Blackboard Building Block [2]) in order to integrate all the sub-systems into existing technology that is already being used by all parties involved in the capstone project. The extension makes use of existing components in blackboard, and adds functionalities that are unique to capstone project courses.

\section{BLACKBOARD LEARN PLATFORM}

Blackboard Learn is an LMS system that provides education institutions a virtual learning environment. The system provides tools that help both instructors and students to take advantage of technology in their learning experience, from virtual classrooms to simple course management. For example, students can keep in touch with their course instructors and their classmates through e- 
The International Journal of E-Learning and Educational Technologies in the Digital Media (IJEETDM) 2(2): 80-85

The Society of Digital Information and Wireless Communications (SDIWC), Apr - 2016 (ISSN: 2410-0439)

mail or message board. Blackboard also enables students to receive and submit assignments, tests and surveys as well as to view their grades as soon as instructors make them available. In addition, Blackboard provides students with a platform to collaborate with each other through features such as groups, collaborate and message boards. A study has shown that $70 \%$ of the student's created site are geared towards group work and group projects [3]. The study found that students were creating websites to manage their class projects or simply for study groups [3]. Since capstone projects are mainly group projects, integrating the different aspects of the capstone projects into existing LMS systems such as Blackboard should improve the collaboration experience of students and ease the management of their project related activities without the need of student initiated virtual study group (known as eTeam [4]).

On the other hand, Blackboard provides instructors with several tools to ease and improve their teaching experience, such as course content, announcements, blogs, and secure and automated testing and grading. In a study that tested whether the reconfigurablity features of LMS systems enables faculty to implement the seven principles of teaching [5] effectively, Wang et. al. provided empirical evidence that LMS systems allow faculty members to implement the seven principles of effective teaching [6]. Moreover, the study showed that the more LMS systems are used, the greater the faculty perceived benefits [6] Therefore, enabling LMS systems to deal with irregular courses such as capstone projects courses contributes to the leveraging of IT to improve the seven teaching principals.

Blackboard provides a complete framework for extending its platforms. Using Building Blocks, developers create new applications or integrate existing tools into the blackboard platforms. Developers can publish their building blocks on Blackboard's building block sites, while users can search and download their desired extensions. For example, the City University of New York (CUNY) uses several building blocks to extend the features and services of Blackboard for its users [7]. Users can suggest building blocks, which are made available upon approval. Some of these building blocks include Collaborate Voice Authoring [8], Soft chalk Publish with Score Center [9], and Tegrity Lecture Capture [10].

The Collaborate Voice Authoring building block allows instructors and students to record audio and post it to a Blackboard voice discussion board. The voice recording can also be sent by e-mail to specific instructors or students. The features of this tool improve students' engagement as well as give instructors the ability to produce audible course content [8].

The Soft chalk Publish building block is a popular software that enables educators to create and share interactive learning content with their students. The popularity of Soft chalk is due to its ease of use. Instructors can build powerful learning content, such as interactive web pages without requiring any programming or mark-up languages. Instead, Soft chalk generates lesson pages automatically. Moreover, the grades from Soft chalk quizzes are automatically added to the grade center in Blackboard [9].

Tegrity is a lecture capture software that can be used by instructors to capture their lectures and post them on Blackboard. The focus of the software is student learning. In addition to viewing the lecture, the building block allows students to interact with the instructor, take notes, set bookmarks and much more. One of the main advantages of Tegrity is the ease of use. For example, instructors do not have to record, convert and upload their lecture videos, but rather simply click the lecture on the browser and the video is automatically uploaded to the right course [10].

Building blocks provide academic institutions the ability to extend and customize Blackboard functionality to meet their specific needs. The goal of our project is to create a building block to manage capstone projects at the department of computer science at King Saud University. The extension will also be available to other institutions to customize and use on their capstone project courses. 
The International Journal of E-Learning and Educational Technologies in the Digital Media (IJEETDM) 2(2): 80-85

The Society of Digital Information and Wireless Communications (SDIWC), Apr - 2016 (ISSN: 2410-0439)

\section{CAPSTONE PROJECT MANAGEMENT SYSTEM (CPMS)}

Prior to using CPMS, the course coordinator, supervisors and students should be added to a blackboard course and students divided into subsection using blackboard merge tool [11]. The coordinator should have the instructor role in the course, so he/she can assign examiners, create assignments, create grading criteria and manage the course as a whole. Each project group in the course consists of a supervisor, one or two examiners and a group of students. In this section, we present the system views as each user has a unique view based on his or her role in the system. For simplification, only the main functionalities of the system, such as examiners assignment, assignments, gradebook and submissions are presented.

\subsection{System Views:}

When a user enters the CPMS course tool, the system opens in the proper view based on his/her role. If the user is the coordinator, he/she will have five tabs: Gradebook, Submissions, Examiner Assignment, Course Assignment, and Switch to Supervisor role. Figure 1 shows an example of the coordinator view.

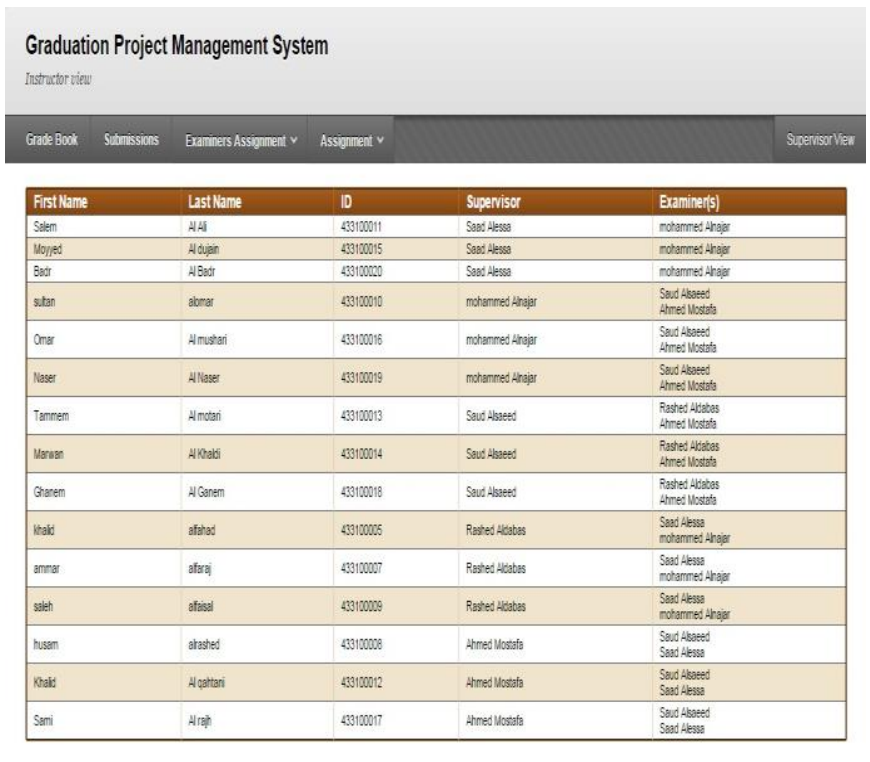

Figure 1. Example of the coordinator view
When a supervisor logs in the system, the homepage page displays the students' information and grades. Supervisors have two tabs: the first tab is the examination tab, where they can select a group assigned them by the coordinator. The second tab is the submissions tab where the submissions of the supervisors own can be found. Figure 2 shows an example the supervisor's view.

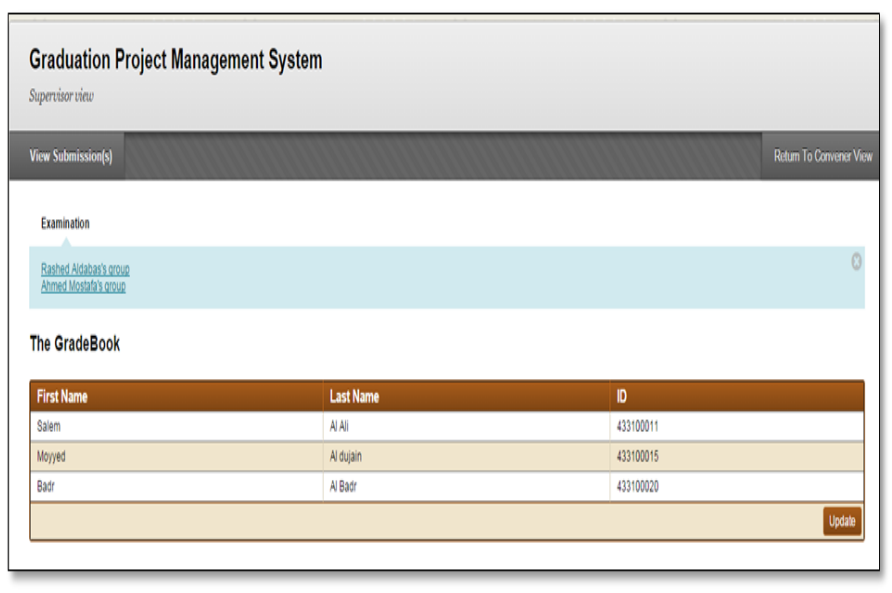

Figure 2. Example of the coordinator view

To get to the examiner's view, the supervisor must first select a group from the examination tab. The examiner's homepage displays the students' information, submissions assigned by the coordinator for grading and their grade columns. The examiner has two tabs; the first tab is the submissions tab, where submissions assigned by the coordinator for grading can be found and graded. The second tab allows the examiner to switch to the supervisor role. Figure 3 shows an example of the examiner view of a particular group.

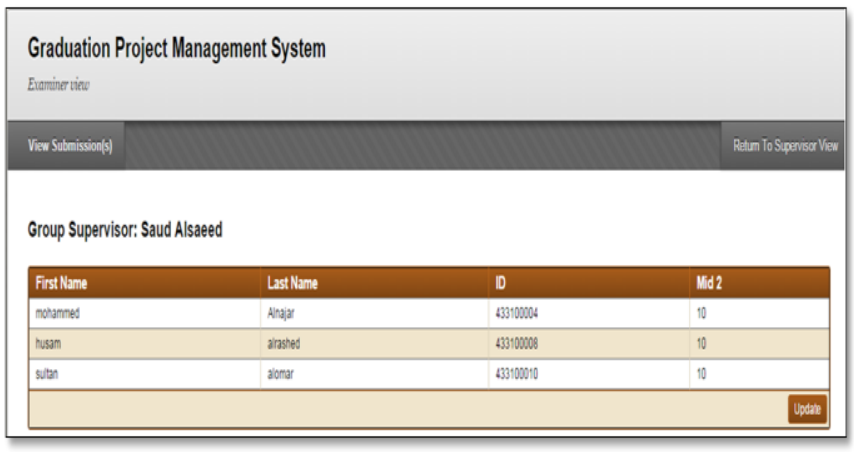

Figure 3. Example of the examiner view 
The International Journal of E-Learning and Educational Technologies in the Digital Media (IJEETDM) 2(2): 80-85

The Society of Digital Information and Wireless Communications (SDIWC), Apr - 2016 (ISSN: 2410-0439)

\subsection{System Functionalities:}

In this section, we present the main functionalities of the CPMS system. These functionalities are examiners assignment, course submissions, course assignments and gradebook.

\subsubsection{Examiners assignment:}

The examiners assignment tab has two options. The first one is used to assign examiners and the second one is to remove an examiner. In order to keep the extra permission, a custom MySQL database is used to stores the examiners and supervisors' relations. If the user is the course coordinator, the examiners assignment tab is visible as shown in figure 1 . The coordinator must assign examiners for each group using the name of group's supervisor and a list of examiners from which to choose. Figure 4 illustrates the examiner assignment page. After assigning all examiners, they will be able to access the submissions and grade columns of their assigned. The coordinator can also remove an examiner from a particular group using the same page.

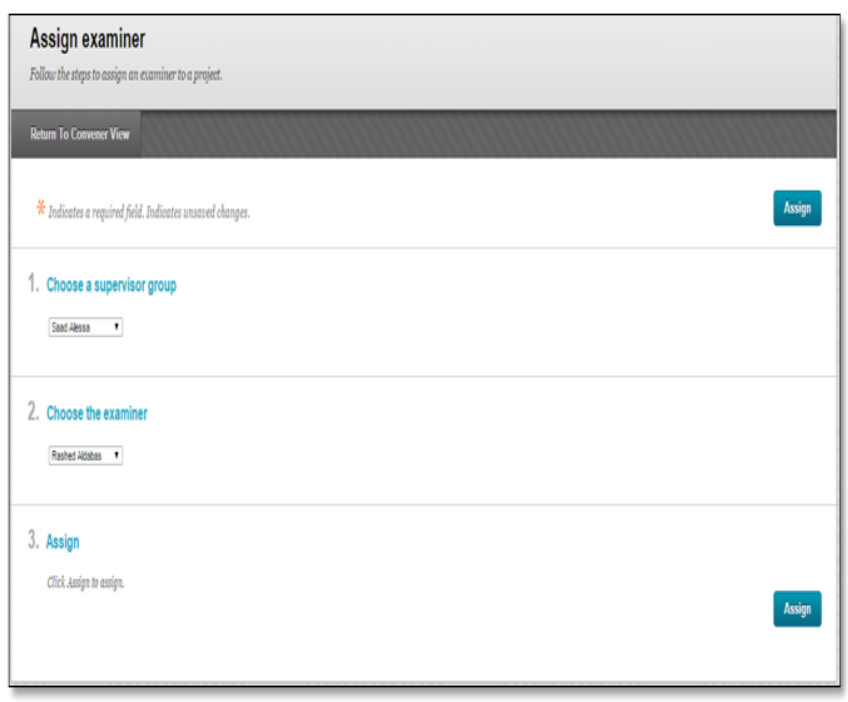

Figure 4. Example of assigning an examiner

\subsubsection{Course Assignments:}

The course coordinator can create assignments throughout the capstone course. For example, at KSU computer science department, the first phase of the project requires students to submit midterm and final reports. The coordinator can create course assignments in order to receive submissions from the students and have them graded by his or her specified examiners. Assignments can also be updated or deleted after creation. In addition to the regular options of creating a blackboard assignment, the coordinator has to select who can grade the assignment. Supervisors, examiners, or both can grade assignments. In the coordinator does not select either option, he or she will be the only one with access to the assignment. Figure 5 shows the assignment creation page.

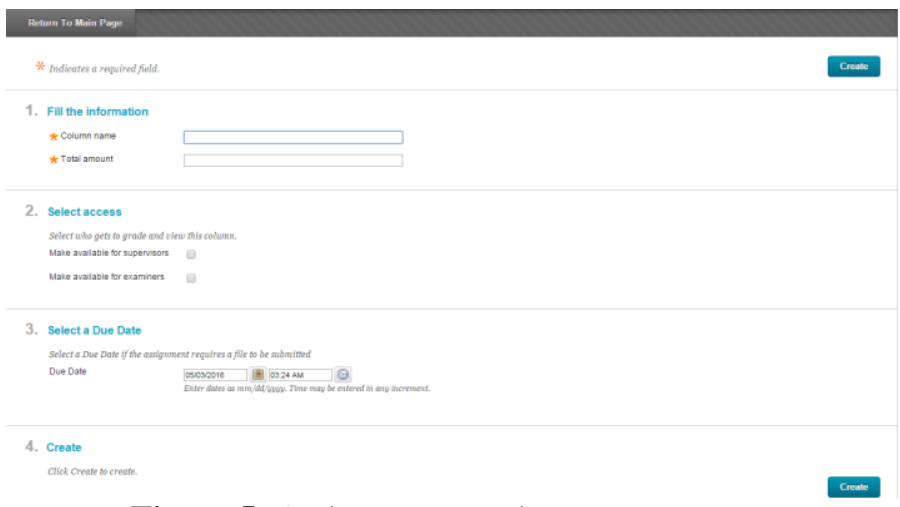

Figure 5: Assignment creation page.

\subsubsection{The Gradebook:}

Blackboard provides a gradebook for instructors and students. Since capstone projects are graded by more than one user, the traditional gradebook has to be customized to fit the specifications of the process. The coordinator can view and update all columns of the gradebook. On the other hand, supervisors can only see the grade of their own students. They should also be able to edit grade columns assigned to them by the coordinator. If an examiner $\operatorname{logs}$ in to an assigned group, the gradebook shows the information of the particular groups and only the gradebook columns that have been assigned to him by the coordinator. Finally, each student should see his gradebook. Both group shared grades and individual grades are shown to students as if it were a regular gradebook. 
The International Journal of E-Learning and Educational Technologies in the Digital Media (IJEETDM) 2(2): 80-85

The Society of Digital Information and Wireless Communications (SDIWC), Apr - 2016 (ISSN: 2410-0439)

\subsubsection{Submissions:}

Once the coordinator creates an assignment, a submission entry is created. Students can submit, view and download assignments through the customized assignment page. Once a student submits an assignment, all the students in the same group as well as the examiners that have access to the assignment can see it. The coordinator can view all submissions. Figure 6 shows the submission page from a student's view. For all individual assignments, regular blackboard assignments can be used.

\section{Submit}

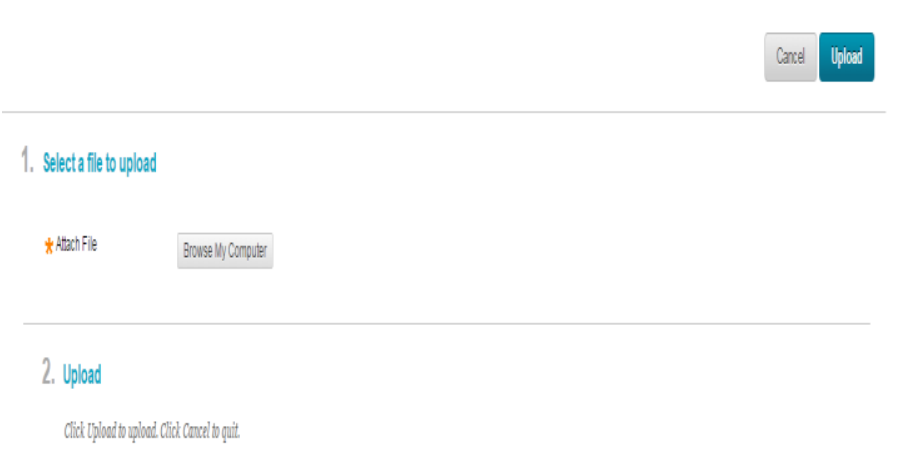

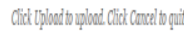

Figure 7: Student's view of submission page.

\subsection{Deployment and Testing:}

The CPMS building block was packaged as a Web Application Archive (.war file) and uploaded to the blackboard server as a course tool and a system tool. CPMS is available for use by any academic institution upon request.

In order to test the system's functionalities, we used a Black Box testing approach and real data from the CSC497 capstone project course at the department of computer science at King Saud University during the spring of 2016. The course contains 12 sections, 34 students, 12 supervisors/examiners and 1 coordinator. The results match those of the current subsystems used by the capstone committee and actual users have successively verified all functionalities.

\section{CONCLUSION}

Blackboard is used by $80 \%$ of the Top 50 Times Higher Education Reputation Ranking in 2014 [10]. It also severs over 20 million K-12 students and is currently used by $92 \%$ of top online bachelor degree programs [12]. Using Building Blocks, institutions can increase the usability of the blackboard system by extending its functionality and tailoring it to meet their needs. In this paper, we introduce a building block called CPMS, designed to manage capstone projects. The system takes advantage of current functionalities of the Blackboard Learn platform and provides a course tool capable of managing group based courses. CPMS allows multiple sections to have one coordinator and several supervisors and examiners. In addition, the CPMS course tool extends the capabilities of the assignment creation, gradebook and submissions in order to allow these tools to behave differently based on the user's role in the capstone project.

\section{REFERENCES}

1. Bradford P., Porciello M., Balkon N., Backus D. (2007): The Blackboard Learning System. The Journal of Educational Technology Systems 35, 301-314

2. Building Blocks Developer Guide Version 9.0. April 2009.

http://www.blackboard.com/partnerships/extensions.aspx

3. Teasley, S. D., \& Lonn, S., (2007) Using learning management systems to support collaborative learning in higher education. Proceedings of the Conference on Computer Supported Collaborative Learning (pp. 717719). Bloomington, IN: Lawrence Erlbaum Associates.

4. Dutton, W. H., Cheong, P. H., \& Park, N. (2003). The social shaping of a virtual learning environment: The case of a university-wide course management system. The Electronic Journal of e-Learning, 2(1)

5. Chickering, A., \& Gamson, Z. F. (1987) Seven principles for good practice in undergraduate education. AAHE Bulletin.

6. Wang, J., Doll, W. J., Deng, X., Park, K., \& Yang, M. G. M. (2013). The impact of faculty perceived reconfigurability of learning management systems on effective teaching practices. Computers \& Education, 61, 146-157.

7. City University of New York Blackboard Building Blocks.

http://www2.cuny.edu/about/administration/offices/cis/c ore-functions/cuny-blackboard/building-blocks/ 
The International Journal of E-Learning and Educational Technologies in the Digital Media (IJEETDM) 2(2): 80-85

The Society of Digital Information and Wireless Communications (SDIWC), Apr - 2016 (ISSN: 2410-0439)

8. Blackboard collaborate Voice Authoring 6.1. July 2012

http://library.blackboard.com/ref/41b87c29-ad51-43bba0f5-405bf1b4ecbb/index.htm

9. Blackboard and SoftChalk. Desktop Integration Guide. June 2014.

https://www.gvtc.org/Portals/62/lms_blackboarddesktop.pdf

10. Tegrity. Educational Pathways Reprint. 6,6 (2007)

11. Blackboard merge tool. http://blackboard.com

12. Blackboard mission statement.

http://www.blackboard.com/about-us/who-we-are.aspx 